\title{
Osteosarcoma of Jaw: A Case Report with Unusal Presentation
}

\section{Priyanka $\mathrm{A}^{1 *}$ and Ashok $\mathrm{A}^{2}$}

${ }^{1}$ Department of Oral Pathology, Sharad Pawar Dental College, India

${ }^{2}$ Department of General Pathology, Sharad Pawar Dental College, India

*Corresponding author: Priyanka Agarwal, Department of Oral Pathology, Sharad Pawar Dental College, Jodhpur, Rajasthan, India, Email: drpriyankaagarwal@gmail.com

\section{Case Report}

Volume 2 Issue 4

Received Date: June 04, 2018

Published Date: July 03, 2018

DOI: $10.23880 / \mathrm{mjccs}-16000163$

\section{Abstract}

In the jaw bones, Osteo Sarcoma accounts for about 4\% of all the primary malignant neoplasms. Low-grade lesions are rare and represent less than $2 \%$ of all osteosarcomas reported in the literature. This article reports on a case of a low grade osteosarcoma of the maxilla. A 30-year-old woman came with a chief complain of recurrent ossifying fibroma of the maxillae. The clinical picture showed a well defined, pedunculated, roughly rectangular growth arising from posterior left maxillary tooth region. An excisional biopsy was performed and diagnosis of low grade osteosarcoma was established and the patient was recommended for oncologic treatment.

Keywords: Osteosarcoma; Ossifying Fibroma; Aggressive Ossifying Fibroma

\section{Introduction}

Osteosarcoma (OS) is the most common primary malignant bone tumor; however, only $5 \%$ of all cases occur in the jaws. The maxilla is less commonly affected than the mandible and in the maxilla the majority of OSs arises in the alveolar ridge and the maxillary antrum. Presenting signs and symptoms of craniofacial osteosarcoma (CFOS) include regional swelling, pain and parasthesia. In addition, unusual clinical presentation such as peri-apical lesion-like appearance has been reported.

In general, osteosarcomas of the jaw are high grade lesions. Low-grade lesions are rare and include the well differentiated intraosseous osteosarcoma (low-grade central osteosarcoma) and parosteal osteosarcomas. Low grade osteosarcoma (LOS; well-differentiated intraosseous osteosarcoma), represents less than $2 \%$ of all osteosarcomas reported in the literature [1]. Because of its rarity and well differentiation, LOS is usually misdiagnosed as a benign lesion.

The author would like to report a case of LOS of the maxilla with extremely unusual presentation in a 30yearold woman.

\section{Case Report}

A 30 yr old female patient reported in the OPD with a chief complain of swelling and growth in the upper jaw region. Patient was apparently alright about 15 days back when she developed an intraoral growth in the maxillary posterior jaw region and extraoral swelling in the maxilla. The swelling was sudden in onset. Initially it was small and increased in size suddenly to present size. Patient had reported earlier in the OPD twice since 6 months for swelling and growth. For which she was treated by 


\section{Medical Journal of Clinical Trials \& Case Studies}

surgical excision, both the times. She was diagnosed as with peripheral ossifying fibroma and aggressive ossifying fibroma for $1^{\text {st }}$ and $2^{\text {nd }}$ visit respectively (Figures $1 \& 2)$

Extraoral findings revealed bilaterally asymmetrical face due to presence of large swelling in the left jaw region, which extends anterio-posteriorly $1 \mathrm{~cm}$ below the orbit of the left eye to the lower border of the left mandible \& mesio -laterally from lateral wall of the left nose thru lower left lip to $3 \mathrm{~cm}$ in front of tragus of ear. The swelling is tender on palpation. Intraoral a well defined, pedunculated, roughly rectangular growth arising from posterior left maxillary tooth region seen. The growth is covering the occlusal surface of 26 and 27.The surface is irregular with surface indentation of teeth (Figure 3). On palpation the growth is tender, soft to firm in consistency, and is not fixed.
In keeping up with the above findings, provisional diagnosis of ossifying fibroma was made, where as CEOT, Osteosarcoma, Chondrosarcoma were considered as differential diagnosis. Routine radiological and blood investigations were performed, which fail to reveal any significant finding. Complete surgical excision was done. The gross specimen macroscopically was grayish brown in color and was soft to firm in consistency. Histopathological finding shows lesional tissue consisting of tumor osteoid with dysplastic osteoblast and fibroblast. The dysplastic osteoblast is of varying shape and size; spindle to oval shaped. They show hyperchromatic nuclei with pleomorphism. Based on these features histopathological diagnosis of Low grade Osteosarcoma was made.

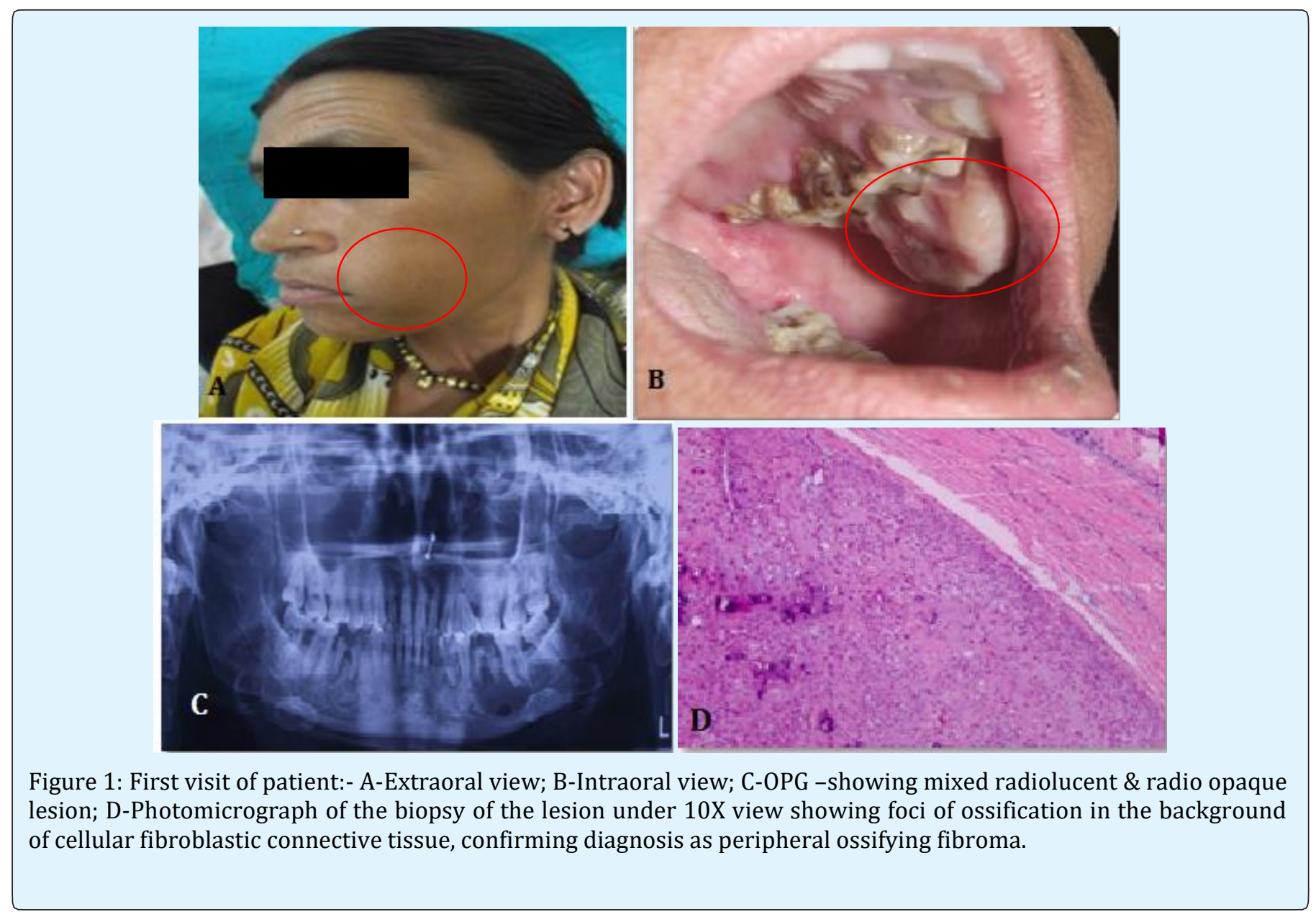

Priyanka A and Ashok A. Osteosarcoma of Jaw: A Case Report with Unusal Presentation. Med J Clin Trials Case Stud 2018, 2(4): 000163. 

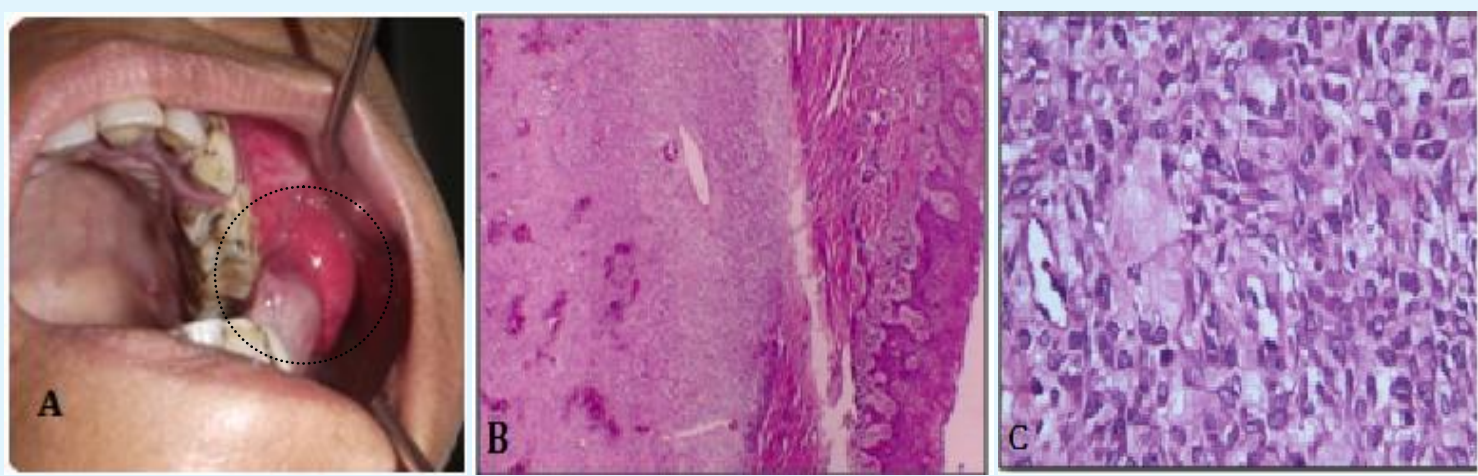

Figure 2: Second visit of patient: A-Intraoral view; B-Photomicrograph of the biopsy of the lesion under 10X view showing foci of ossification in the background of highly cellular fibroblastic connective tissue; C- Photomicrograph of the biopsy of the lesion under $40 \mathrm{X}$ view showing plump fibroblast with myxoid stroma confirming diagnosis of aggressive ossifying fibroma.
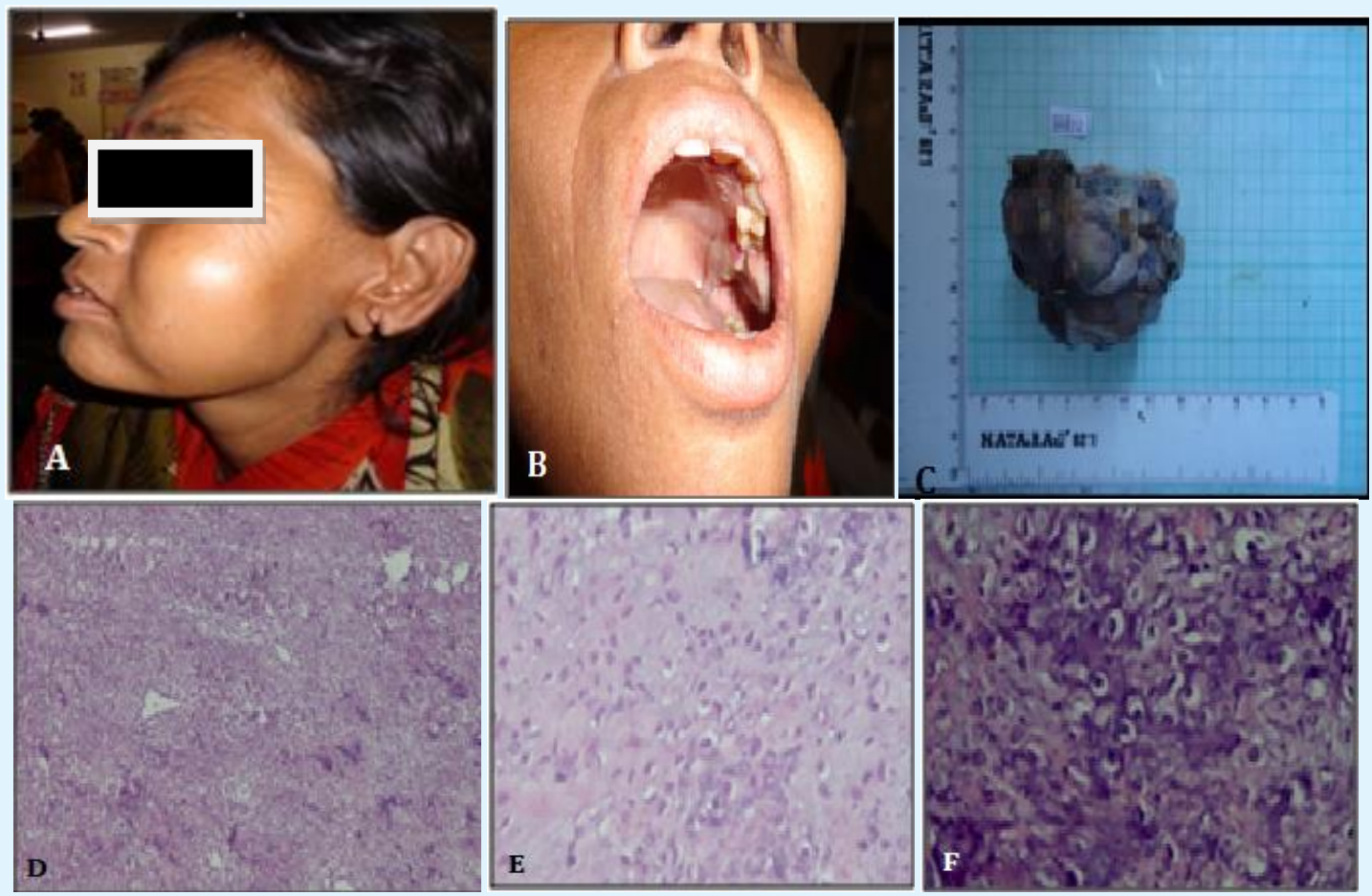

Figure 3: Third visit of patient: A-Extraoral view; B-Intraoral view; C-Gross Specimen; D-Photomicrograph of the biopsy of the lesion under 10X view showing foci of ossification in the background of highly cellular fibroblastic connective tissue; E, F-Photomicrograph of the biopsy of the lesion under 40X view showing tumor osteoid with dysplastic osteoblast and fibroblast confirming diagnosis of Low grade Osteosarcoma. 


\section{Medical Journal of Clinical Trials \& Case Studies}

\section{Discussion}

Osteosarcoma (OS) is the commonest primary neoplasm of the bone, typically affecting the metaphysis of the femur or tibia in children and young adults; it is the third commonest malignancy in adolescents [2,3]. About $10 \%$ of OS occurs in the head and neck; those occurring in the jaws account for $4 \%[3,4]$. OSs of the jaws is very rare and has a mild male predilection. At the time of diagnosis, the patients are approximately 2 decades older than those with extragnathic OS, which have a peak incidence between the ages of 10 and 14 years. However, most Gnathic OSs is high-grade lesions and demonstrate a high mortality rate associated with local invasion that is usually difficult to control [5]. Similar to the conventional type of osteosarcoma, Lowgrade osteosarcoma (LOS; well-differentiated intraosseous osteosarcoma), has a predilection for the body of the mandible, and usually presents with a long-standing painless swelling $[1,6]$. The commonest signs and symptoms associated with jaw OS, as reported in the literature, consist of persistent pain, swelling, and paresthesia/anesthesia $[7,8]$.

Several histologically unusual features of OS such as epitheliod or small cell subtypes and variable radiographic appearances have been reported previously, which confirm the importance of meticulous evaluation of the patients with intraosseous lesions resembling OS; but a few cases with uncommon clinical presentation have been described and based on our knowledge the present case is the first reported OS with clinical presentation similar to "peripheral ossifying fibroma" \& initially diagnosed as ossifying fibroma [9-12].

In other reported rare clinical or radiographic presentations of OS, Soares et. alreported a patient with OS erroneously diagnosed as a periapical lesion and this delay in ac-curate diagnosis led to death of the patient after about 2 years. Yamamoto et al. described a case of maxillary OS with extremely unusual image findings in an 11-year-old boy and associated this strange feature with initial phase of tumor progression. Babazade et al. reported an uncommon bilateral metachronous OS of the mandibular body in a 27-year-old man and recommended that physicians should be aware that OS can occur in different sites as a true multicentric lesion. Shakib et al. repotted a case in a 42 -year female patient with epulis fissuratum like feature [13-16].

Histological diagnosis of OF and AOF was made in our case in her previous visits, which lead us to a diagnosis of recurrent OF again, but to the surprise the microscopic features of the lesion presented lead to the diagnosis of OS (low grade). To the best of our knowledge this is the first case reported with an unusual clinical presentation along with histological low grade type OS in maxillae. Sinha et al had reported a low grade osteosarcoma in mandible [5].

The differential diagnosis of LOS includes benign and low-grade spindle lesions such as fibrous dysplasia, ossifying fibroma, chondromyxoid fibroma, unclassifiable fibro-osseous lesions, as well as desmoplastic fibroma. Resection with wide surgical margins is the most important factor for prognosis and provides a 5-year survival rate of $80 \%$ [17]. Bony margins for resection should at least be $2 \mathrm{~cm}$ from the clinical-radiographic edge or the nearest suture in the midface. Soft tissue margins around an osteosarcoma resection should be 2 $\mathrm{cm}$ or more and assessed with frozen sections. Adjuvant chemotherapy or radiotherapy seems to be inefficacious in cases of LGCO [18]. Recurrences of LGCO may exhibit a higher histopathological grade or dedifferentiation with potential for metastases that can lead to the death of the patient [19].

The transformation of a low-grade central osteosarcoma into a high-grade osteosarcoma on recurrence has been reported in $15 \%$ of the patients [18].

Low-grade central osteosarcoma is a rare neoplasm that histopathologically offers the potential for misdiagnosis as benign condition, most specifically fibrous dysplasia. Careful attention to clinical, radiographic, and microscopic findings is necessary to ensure establishment of the correct diagnosis, thus helping to prevent incorrect treatment and unfortunate outcome. Prognosis is good if an early diagnosis of the lesion is made with prompt surgical intervention.

In summary, we have presented an unusual case of LOS of the maxilla in a 42-year-old woman.

\section{References}

1. Diniz AF, Filho JA, Alencar Rde C, Garcia RR, Silva MR, et al. (2007) Low-grade central osteosarcoma of the mandible: a case study report. Oral Surg Oral Med Oral Pathol Oral Radiol Endod 103(2): 246-252.

2. Klein MJ, Siegal GP (2006) Osteosarcoma: anatomic and histologic variants. J Clin Pathol 125(4): 555-581. 


\section{Medical Journal of Clinical Trials \& Case Studies}

3. Alves FA, Lopes MA, Ikeda MK, Kowalski LP, Almeida OP (2003) Oral metastasis of telangiectatic osteosarcoma. Oral Dis 9(2): 104-106.

4. August M, Magennis P, Dewitt D (1997) Osteogenic sarcoma of the jaws: Factors influencing prognosis. J Oral Maxillofac Surg 26(3): 198-204.

5. Sinha R, Roy Chowdhury SK, Chattopadhyay PK, Rajkumar K (2010) Low-grade osteosarcoma of the mandible. J Maxillofac Oral Surg 9(2): 186-190.

6. Guadagnolo BA, Zagars GK, Raymond AK, Benjamin RS, Sturgis EM (2009) Osteosarcoma of the jaw/craniofacial region: outcomes after multimodality treatment. Cancer 115(14): 32623270 .

7. Kassir RR, Rassekh CH, Kinsella JB, Segas J, Carrau RL, et al. (1997) Osteosarcoma of the head and neck: Meta-analysis of nonrandomized studies. Laryngoscope 107(1): 56-61.

8. Cohen IJ (1993) Significant recent advances in the treatment of osteosarcoma. J Med Sci 29: 748-753.

9. Carlos-Bregni R, Contreras E, Hiraki KR, Vargas PA, Leon JE, et al. (2008) Epithelioid osteosarcoma of the mandi-ble: a rare case with unusual immunoprofile. Oral Surg Oral Med Oral Pathol Oral Radiol Endod 105(2): e47-52.

10. Kaveri H, Rekha K, Punnya VA (2009) Epithelioid osteosarcoma of the maxilla: report of an unusual case. Br J Oral Maxillofac Surg 47(2): 143-145.

11. Uma K, Cherian G, Nayak V, Patil S (2011) Small cell osteosar-coma of the mandible: Case report and review of its diagnostic aspects. J Oral Maxillofac Pathol 15(3): 330-334.
12. Padilla RJ, Murrah VA (2011) The spectrum of gnathic osteosarcoma: Caveats for the clinician and the pathologist. Head Neck Pathol 5(1): 92-99.

13. Soares RC, Soares AF, Souza LB, Santos AL, Pinto LP (2005) Osteosarcoma of mandible initially resembling lesion of dental periapex: a case report. Braz J Otorhinolaryngol 71(2): 242-245.

14. Yamamoto A, Sakamoto J, Muramatsu T, Hashimoto S, Shibahara T, et al. (2011) Osteosarcoma of maxilla with unusual image findings in child. Bull Tokyo Dent Coll 52(4): 201-207.

15. Babazade F, Mortazavi H, Jalalian H (2011) Bilateral metachronous osteosarcoma of the mandibular body: a case report. Chang Gung Med J 34(6): 66-69.

16. Shakib PA, Foroughi R, Seyedmajidi M (2013) Osteosarcoma of the Maxilla: A Rare Case with Unusual Clinical Presentation. J Dent Res Dent Clin Dent Prospect 7(3): 177-181.

17. Mardinger O, Givol N, Talmi YP, Taicher S (2001) Osteosarcoma of the jaw. The Chaim Sheba Medical Center experience. Oral Surgery, Oral Medicine, Oral Pathology, Oral Radiology, and Endodontology 91(4): 445-451.

18. Kurt AM, Unni KK, McLeod RA, Pritchard DJ (1990) Low-grade intraosseous osteosarcoma. Cancer 65(6): 1418-1428.

19. Bennett JH, Thomas G, Evans AW, Speight PM (2000) Osteosarcoma of the jaws: a 30-year retrospective review. Oral Surg Oral Med Oral Pathol Oral Radiol Endod 90(3): 323-332. 